\title{
Comparison of Control Algorithms Using a Generalized Model for a Human with an Exoskeleton
}

\author{
Antonio Concha ${ }^{\mathrm{a}}$, Francisco Emmanuel González Sánchez ${ }^{\mathrm{b}}$, Efrain Ramírez Velasco ${ }^{\mathrm{c}}$, \\ Martín Sánchez ${ }^{\text {, }}$ Suresh Kumar Gadi, ${ }^{\text {,** }}$ \\ ${ }^{a}$ Facultad de Ingeniería Mecánica y Eléctrica, Universidad de Colima, Colima \\ ${ }^{\mathrm{b}}$ Facultad de Ingeniería Mecánica y Eléctrica, Universidad Autónoma de Coahuila, Torreón \\ ${ }^{\mathrm{c}}$ Departamento de Eléctrica-Electrónica, Instituto Tecnológico de Aguascalientes
}

\begin{abstract}
This article proposes a pictorial representation of a generalized model for a human with an exoskeleton. This model is useful for comparing control techniques and allows identifying the sensor and actuator requirements for a particular control algorithm. Moreover, the pictorial model displays the control algorithms in block diagrams showing the details of these algorithms. In order to show the utility of this model, the following four control schemes are compared: 1) Kazerooni's algorithm, 2) BLEEX's algorithm, 3) technique inspired by fictitious gain, and 4) Force control with velocity and position feedback. The hardware and software requirements for these control algorithms are also discussed.
\end{abstract}

Keywords: Force augmenting device, exoskeletons, Human-Robot Interaction, closed-loop control.

\section{Introduction}

There is a growing interest in the area of human-robot interactions[1]-[3], which are of two types: 1) Teleoperation, where mechanical forces between humans and robot arms are not exchanged; and 2) Human-exoskeleton interaction, where the robot and the human arms produce reaction forces on each other. This article is focused on the second kind of interaction, where the human and exoskeleton are in contact all the time. The exoskeletons, also called in this document as force augmenting devices (FADs), can be used in various applications ranging from active prosthetics, material handling, military, space research, etc. [4]-[8]. Since the FADs are always in contact with the human, the stability analysis of their control algorithms is of extreme importance.

In the process of designing and building of an exoskeleton several control algorithms, applied to this system, are compared in order to select the one producing the best performance. Moreover, the actuators and sensors of the exoskeleton, that are compatible with those control techniques, need to be identified. In this article, a pictorial representation of any FAD is presented, which allows identifying the sensors and actuators required for a specific control technique. This representation permits comparing four control schemes, whose hardware and software requirements are also found. These control methodologies are the following: 1) Kazerooni's algorithm [6], 2) BLEEX's algorithm [7], 3) technique inspired by fictitious gain [8], and 4) Force control with velocity and position feedback [9]. Next section presents the proposed generalized human-FAD interaction model, and the four control schemes applied to it are studied and compared in Sections 2 to 5.

\footnotetext{
* Corresponding author. Tel. \& fax: (+52 1) 8717570239

E-mail address: research@skgadi.com
}

Manuscript History:

Received 13 January, 2018, Revised 27 March, 2018, Accepted 28 March, 2018, Published 31 March, 2018

e-ISSN: 2289-7771

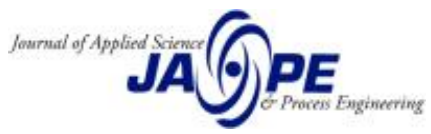




\section{General representation of a Human-Robot interaction}

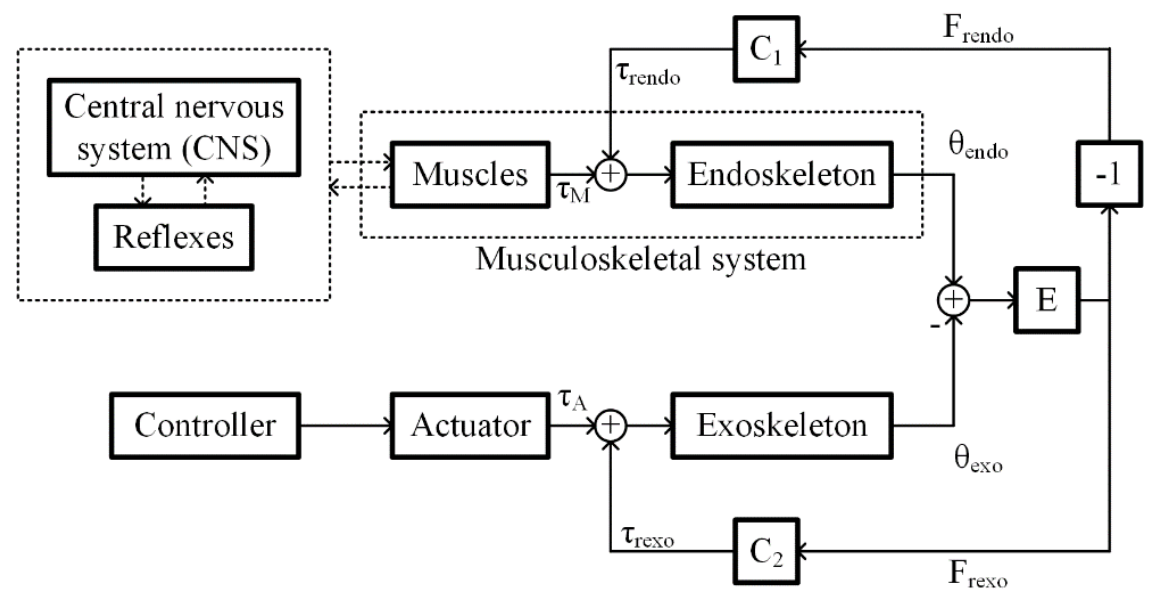

Figure 1. Block diagram showing a general scheme of Human-Robot interaction.

Figure 1 shows a block diagram depicting a human arm (HA) - force augmenting device (FAD) interaction, where two controllers work in parallel, one consists in the Central nervous system of a human and another operates the actuator of the FAD. The human operator generates the desired trajectory and exerts torques that permits the FAD to follow the desired trajectories closely. The electronics in the exoskeleton measures the human interaction with sensors and provides low mechanical impedance in the human's desired trajectory with the help of actuators [9].

The blocks: Central nervous system (CNS), Reflexes, Muscles and Endoskeleton represent the dynamics associated with the human arm movement. The CNS performs the Coordinate transformation, the Trajectory planning, and the Motor command generation [10]-[12]. Hence the CNS generates the desired trajectory and passes the information to the spinal cord. A closed-loop feedback control is executed by the reflexes in the spinal cord in order to move the arms, whose trajectory mimics the desired human arm trajectory as closelv as possible [13], [14].

The difference between the human arm nosition $\theta_{\text {mads and }}$ the exoskeletnn arm nosition $\theta_{\text {exo }}$ causes a force, which is written as $F_{\text {rexo }}=-F_{\text {rendo }}=E\left(\theta_{\text {endo }}-\theta_{\text {exo }}\right)$, where $F_{\text {rexo }}$ and $F_{\text {rendn are the }}$ reaction force generated on the exoskeleton and the human arm respertively. The term $E($.$) is a$ nonlinear function, which maps the difference between $\theta_{\text {endo }}$ and $\theta_{c m}$ to $F_{\text {rexo }}$ and $F_{r e n d n}$. The reaction torcure exnerienced by the human arm $\tau_{\text {wndo }}$ and exoskeleton arm $\tau_{\text {rexo }}$ is given by $\tau_{\text {manto }}=C_{1} F_{\text {rendo }}$ and $\tau_{\text {rexo }}=C_{2} F_{\text {rexo }}$, respectively, where $C_{1}$ and $C_{2}$ are positive constants. Moreover, $\tau_{M}$ is the torque exerted by the muscles, $\tau_{A}$ is the torque produced by the exoskeleton's actuators. Usinally the objective of the control algorithms is to generate $\tau_{A}$ proportional to $\tau_{M}$. The constant $K_{\Delta}$ is an amplification factor. In other words, the FAD amplifies the muscle power by a factor of $K_{A}$. If a value of $K_{A}<1$ is selected, the FAD attenuates the torque exerted by the human mucrle through the production of an opposite torque. It is worth mentioning that FADs with $K_{A}<1$ are used in rehabilitation robots [15].

Figure 1 does not show the implementation of the controller of the FAD. In the next section four control algorithms for the FAD are implemented and added to the model presented in Figure 1. The difference between them and their hardware requirements will be identified. 


\section{Control schemes}

\subsection{Kazerooni's algorithm}

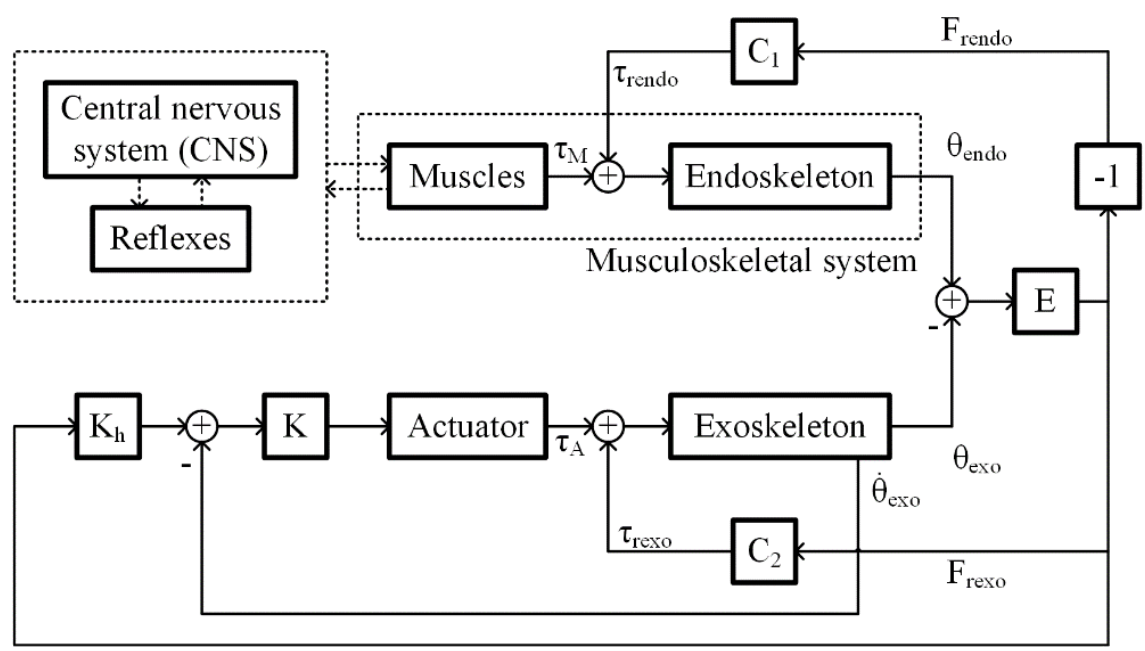

Figure 2: Block diagram showing Kazerooni's algorithm applied to Human-FAD interaction.

Figure 2 depicts the control scheme presented by Kazerooni in [16], where the author uses linear dynamic models to represent the dynamics of the CNS, endoskeleton, and function $E($.$) . Author$ assumes that $K_{h}$ and $K$ are linear dynamic systems. Through this control scheme, the velocity of the exoskeleton arm is controlled. The difference between the human arm position and the exoskeleton nne rauses a velocity in the exoskeleton arm that allows cancelling this difference in position. Signal $F_{\text {rexo }}$ is measured by means a force sensor, and the exoskeleton arm position remains stationary in the case that the user is having no interaction with the force sensor.

In Figure 2 it can be observed that the controller requires two inputs, one is the velocity of the exoskeleton arm and the other input comes from the HA-FAD interaction force. Hence a force sensor and an encoder or a tachogenerator is required.

\subsection{BLEEX (Berkeley Robotics \& Human Engineering Laboratory) Algorithm}

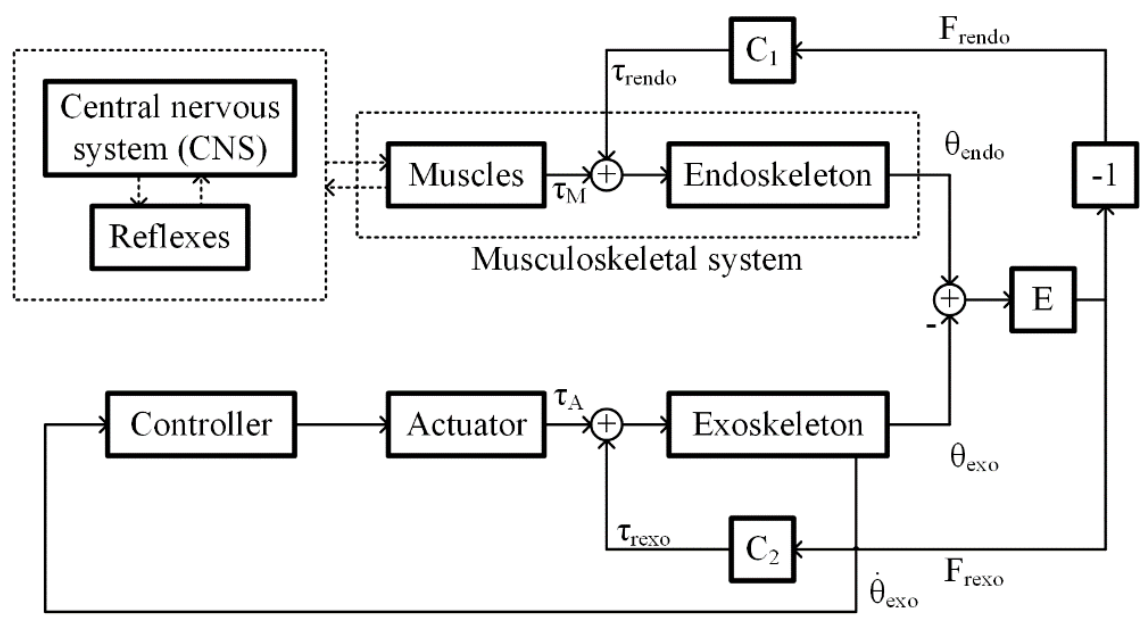

Figure 3: Block diagram showing BLEEX algorithm applied to Human-FAD interaction. 
Figure 3 shows the BLEEX control scheme proposed in [17], [18], which does not use any force sensor. A positive feedback lnop is used to increase the sensitivity of the FAD to external disturbances. The controller $C(s)$ is given by $C(s)=(1-\alpha) G(s)$, where $G(s)$ is the exoskeleton dynamics and $\alpha$ is an augmentation factor. Signal $\tau_{\text {rexo }}$ introduces external disturbances into the positive feedback system. Due to the high sensitivity of the FAD controller towards external disturbances, the exoskeleton arm follows the human arm. It is important to mention that the design of the controller needs the knowledge of an accurate model of the actuator and the inverse model of the exoskeleton arm.

From Figure 3 it can be observed that the controller uses only one feedback loop. This controller estimates the torque exerted by the HA-FAD interaction by computing the perturbations in the exoskeleton velocity. This helps us to identify that the actuator should be bidirectional, i.e. its position should be sensitive to both the torque from the actuator and the force from the HA-FAD interaction. Actuators based on ball-screw mechanisms are not bidirectional, hence they should be avoided.

\subsection{Algorithm inspired by fictitious gain}

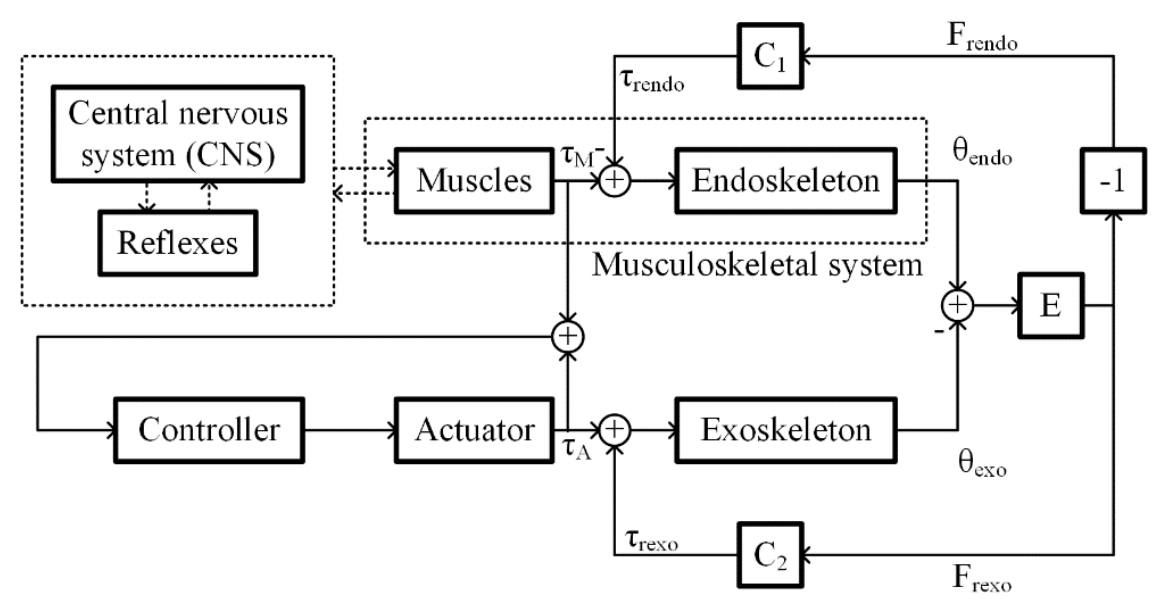

Figure 4. Block diagram showing the algorithm inspired by fictitious gain applied to Human-FAD interaction.

Figure 4 shows a control scheme, inspired by a fictitious gain, presented in [19]. This control scheme needs a positive feedback, which consist in the sum of the torques exerted by the muscles and the actuator. As the algorithm mentioned in the previous subsection, the actuator inverse dynamics is employed by the controller. The torque exerted by the muscles can be estimated by an Electromyography (EMG) sensor, a muscle hardness sensor, or a muscle fiber expansion sensor. Since this control scheme uses a positive feedback, the closed-loop sensitivity of the torque exerted by the muscles, is high. The author of this algorithm also proposes a methodology for adapting this algorithm to users that suffer tremors.

From Figure 4, it can be shown that the controller receives information from the torque exerted by muscles, hence a sensor connected to muscle is required. 


\subsection{Force control with velocity and position feedback}

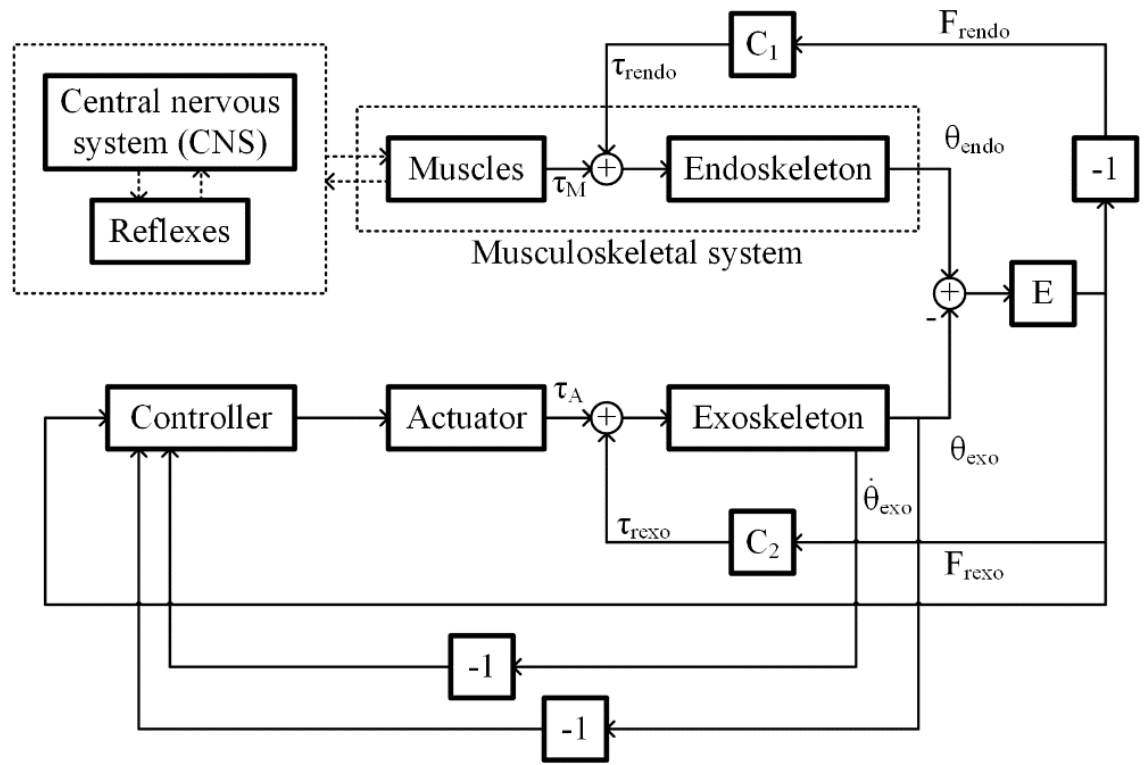

Figure 4. Block diagram showing the force control algorithm with position and velocity feedback applied to Human-FAD interaction.

In this control scheme, presented in [9], authors use a linear model for the CNS, spinal cord, muscles and endoskeleton human arm; and $E($.$) is approximated as a constant. The actuator$ dynamics is ignored hv introducing its inverse dynamics into the controller, which provides an amplifying effect of $\tau_{\text {rexo }}$. The actuator does not provide any torque while the human arm is released, which will bring the exoskeleton to the equilibrium point. Additionally, the controller provides a velocity and position feedback for obtaining the desired performance under no human contact. This control scheme is similar to the Kazerooni's control scheme with a position feedback. It is worth mentioning that the authors of [20] present a methodology to calculate the upper-limit of the augmentation factor. It is observed that the human-FAD interaction would be stable for any value of the augmentation factor if the internal delay of the human reflex action is zero.

From Figure 5, it can be observed that controller requires three sensors, which are position, velocity and force sensors.

\subsection{Comparison between the controllers}

Table 1 presents a comparison between the four control schemes aforementioned. It is worth mentioning that all these controllers guarantee closed-loop stability, and their proofs are omitted and can be found in the corresponding references. 
Table 1. Comparison between the four control algorithms under study

\begin{tabular}{|c|c|c|c|c|}
\hline & $\begin{array}{l}\text { Kazerooni's } \\
\text { algorithm }\end{array}$ & $\begin{array}{l}\text { BLEEX's } \\
\text { algorithm }\end{array}$ & $\begin{array}{c}\text { Algorithm } \\
\text { inspired by } \\
\text { fictitious gain }\end{array}$ & $\begin{array}{c}\text { Force control } \\
\text { with velocity and } \\
\text { position feedback }\end{array}$ \\
\hline Sensors used & Force sensor & $\begin{array}{l}\text { Encoder or } \\
\text { tachogenerator }\end{array}$ & $\begin{array}{l}\text { Electromyography } \\
\text { (EMG) sensor }\end{array}$ & Force sensor \\
\hline $\begin{array}{l}\text { Disadvantages } \\
\text { with sensors }\end{array}$ & $\begin{array}{l}\text { Since the } \\
\text { exoskeleton may } \\
\text { make contact at } \\
\text { various points, } \\
\text { placing a force } \\
\text { sensor is tricky. }\end{array}$ & None & $\begin{array}{l}\text { 1. Placing EMG } \\
\text { sensor is difficult. } \\
\text { 2. Processing } \\
\text { EMG signal is } \\
\text { difficult compared } \\
\text { to processing a } \\
\text { force sensor } \\
\text { signal. } \\
\text { 3. Calibrating } \\
\text { EMG sensor is } \\
\text { time-consuming }\end{array}$ & $\begin{array}{l}\text { Since the } \\
\text { exoskeleton may } \\
\text { make contact at } \\
\text { various points, } \\
\text { placing a force } \\
\text { sensor is tricky. }\end{array}$ \\
\hline $\begin{array}{l}\text { Control } \\
\text { algorithm } \\
\text { complexity }\end{array}$ & $\begin{array}{l}\text { Easy to } \\
\text { implement }\end{array}$ & $\begin{array}{l}\text { Difficult: } \\
\text { 1. The model should } \\
\text { be accurate. } \\
\text { 2. Parameters should } \\
\text { be estimated } \\
\text { accurately. } \\
\text { 3. Controller should } \\
\text { implement the } \\
\text { inverse dynamics }\end{array}$ & $\begin{array}{l}\text { Difficult to } \\
\text { implement: } \\
\text { 1. Parameters } \\
\text { should be } \\
\text { estimated } \\
\text { accurately. } \\
\text { 2. Controller } \\
\text { should implement } \\
\text { the inverse } \\
\text { dynamics }\end{array}$ & $\begin{array}{l}\text { Easy to } \\
\text { implement }\end{array}$ \\
\hline $\begin{array}{l}\text { Limitations of } \\
\text { the control } \\
\text { scheme }\end{array}$ & $\begin{array}{l}\text { Users do not } \\
\text { experience part } \\
\text { of the load that } \\
\text { they are handling } \\
\text { when the } \\
\text { exoskeleton arm } \\
\text { is stationary }\end{array}$ & $\begin{array}{l}\text { 1. Stability is not } \\
\text { guaranteed. } \\
2 \text {. The algorithm may } \\
\text { not differentiate } \\
\text { between } \\
\text { perturbations caused } \\
\text { by human and } \\
\text { external sources. }\end{array}$ & $\begin{array}{l}\text { There is a } \\
\text { limitation on the } \\
\text { mass of the } \\
\text { exoskeleton } \\
\text { structure. }\end{array}$ & $\begin{array}{l}\text { Requires position, } \\
\text { velocity, and } \\
\text { interaction force } \\
\text { feedback. }\end{array}$ \\
\hline
\end{tabular}

\section{Conclusions}

A generalized model of human-robot interaction is proposed, which is used for comparing the following control schemes of exoskeletons: a) Kazerooni's algorithm, 2) BLEEX's algorithm, 3) technique inspired by fictitious gain, and 4) Force control with velocity and position feedback. By comparing these algorithms, it is concluded that using a force or an Electromyography (EMG) sensor is a good option to get stable interaction between the human and the exoskeletons. Moreover, it is shown that a EMG sensor can be replaced by a muscle hardness sensor or a muscle fiber expansion sensor. Finally, a stable operation of the exoskeleton, used by a person suffering from tremor, is guaranteed if the controller contains filters. 


\section{References}

[1] Nagarajan, U., Aguirre-Ollinger, G., and Goswami, A. (2016). Integral admittance shaping: A unified framework for active exoskeleton control, Rob. Auton. Syst., Vol. 75, 310-324.

[2] Gopura, R. A. R. C., Bandara, D. S. V., Kiguchi, K. and Mann, G. K. I. (2016) "Developments in hardware systems of active upper-limb exoskeleton robots: A review," Rob. Auton. Syst., Vol. 75, 203-220.

[3] Manns, P. Sreenivasa, M. Millard, M. and Mombaur,K. (2017). Motion Optimization and Parameter Identification for a Human and Lower Back Exoskeleton Model, IEEE Robot. Autom. Lett., Vol. 2, No. 3, 1564-1570.

[4] Dellon, B. and Matsuoka, Y. (2007). Prosthetics, Exoskeletons, and Rehabilitation [Grand Challenges of Robotics]," IEEE Robot. Autom. Mag., vol. 14, no. 1, pp. 30-34, Mar. 2007.

[5] Makinson, J. B., Bodine, D. P., \& Fick, B. R. (1969). Machine augmentation of human strength and endurance Hardiman I prototype project (No. S-69-1116). General Electric Co Schenectady NY Specialty Materials Handling Products Operation.

[6] Jansen, J., Richardson, B, Pin, F., Lind, R., and Birdwell, J. (2000). Exoskeleton for Soldier Enhancement Systems Feasibility Study, Oak Ridge, Tennessee 37831.

[7] Schiele, A. and Visentin, G. (2008). Exoskeleton for the Human Arm, in Particular for Space Applications, United States Pat. $7410338 B$.

[8] Guizzo E., and Goldstein, H. (2005). The Rise of the Body Bots [robotic exoskeletons]," IEEE Spectr., vol. 42, no. 10 , pp. 50-56, 2005.

[9] Lee, S. and Sankai,Y. (2002). Power Assist Control For Leg With Hal-3 Based on Virtual Torque and Impedance Adjustment, Systems, Man and Cybernetics, IEEE International Conference on, Vol. 4.

[10] Schweighofer, N. Arbib, M. A. and Kawato, M. (1998). Role of the Cerebellum in Reaching Movements in Humans. I. Distributed Inverse Dynamics Control, Eur. J. Neurosci., Vol. 10, No. 1, 86-94.

[11] Shaikh, A. G., Meng,H. and Angelaki, D. E. (2004). Multiple Reference Frames for Motion in the Primate Cerebellum," J. Neurosci., Vol. 24, No. 19, 4491-4497.

[12] Bastian, A.J., Martin, T.A., Keating, J.G. and Thach, W.T. (1996). Cerebellar Ataxia: Abnormal Control of Interaction Torques Across Multiple Joints, J. Neurophysiol., Vol. 76, No. 1, 492-509.

[13] McIntyre, J. and Bizzi, E. (1993). Servo Hypotheses for the Biological Control of Movement, J. Mot. Behav., Vol. 25, No. 3, 193-202.

[14] Randall F.J and Ostry,D. (1990). Trajectories of Human Multi-Joint Arm Movements: Evidence of Joint Level Planning, Experimental Robotics I, 594-613.

[15] He, W., Ge, S. S., Li, Y., Chew, E., and Ng, Y. S. (2015). Neural Network Control of a Rehabilitation Robot by State and Output Feedback. Journal of Intelligent \& Robotic Systems, Vol. 80, No.1, 15-31.

[16] Kazerooni, H. (1988). Human Machine Interaction via the Transfer of Power and Information Signals, ASME Winter Annu. Meet.

[17] Kazerooni, H., Racine, J.L., Huang, L. and Steger, R. (2005). On the control of the berkeley lower extremity exoskeleton (BLEEX), Proceedings of the 2005 IEEE International Conference on Robotics and Automation, 2005. ICRA 2005., 4353-4360.

[18] Kazerooni, H. and Steger, R. (2006). The Berkeley Lower Extremity Exoskeleton, J. Dyn. Syst. Meas. Control, Vol. 128, No. 1, 14-25.

[19] Kong, K. and Tomizuka, M.(2009). Control of Exoskeletons Inspired by Fictitious Gain in Human Model, IEEE/ASME Trans. Mechatronics, Vol. 14, No. 6, 689-698.

[20] Gadi, S. K., Osorio-Cordero, A., Lozano-Leal, R. and Garrido, R. A.(2017). Stability Analysis of a Human Arm Interacting with a Force Augmenting Device, J. Intell. Robot. Syst. Theory Appl., Vol. 86, No. 2, 215224. 